\title{
Stage IIIC2 Uterine Corpus Cancer AJCC v8
}

National Cancer Institute

\section{Source}

National Cancer Institute. Stage IIIC2 Uterine Corpus Cancer A/CC v8. NCI Thesaurus.

Code C139811.

Stage IIIC2 includes: T1-T3, N2/N2mi/N2a, M0. T1: Uterine corpus carcinoma or carcinosarcoma with tumor confined to the corpus uteri, including endocervical glandular involvement. T2: Uterine corpus carcinoma or carcinosarcoma with tumor invading the stromal connective tissue of the cervix but not extending beyond the uterus. Does not include endocervical glandular involvement. T3: Uterine corpus carcinoma or carcinosarcoma with tumor involving serosa, adnexa, vagina, or parametrium. N2: Regional lymph node metastasis to para-aortic lymph nodes, with or without positive pelvic lymph nodes. N2mi: Regional lymph node metastasis (greater than $0.2 \mathrm{~mm}$ but not greater than $2.0 \mathrm{~mm}$ in diameter) to para-aortic lymph nodes, with or without positive pelvic lymph nodes. N2a: Regional lymph node metastasis (greater than $2.0 \mathrm{~mm}$ in diameter) to para-aortic lymph nodes, with or without positive pelvic lymph nodes. MO: No distant metastasis. (from AJCC 8th Ed.) 